\title{
Metabolism of Anethole Dithiolethione by Rat and Human Liver Microsomes: Formation of Various Products Deriving from Its O-Demethylation and S-Oxidation. Involvement of Cytochromes P450 and Flavin Monooxygenases in These Pathways ${ }^{\text {[ }}$
}

\author{
Martin Dulac, Amor Sassi, Citra Nagarathinan, Marie-Odile Christen, Patrick M. Dansette, \\ Daniel Mansuy, and Jean-Luc Boucher
}

Laboratoire de Chimie et Biochimie Pharmacologiques et Toxicologiques, CNRS UMR 8601, University Paris Descartes, Paris, France (M.D., A.S., C.N., P.D., D.M., J.-L.B.) and Marie-Odile Christen Behavior, Paris, France (M.-O.C.)

Received May 27, 2018; accepted July 9, 2018

\begin{abstract}
A study of the metabolism of anethole dithiolethione (ADT, 5(p-methoxyphenyl)-3H-1,2-dithiole-3-thione) by rat and human liver microsomes showed the formation of the corresponding $S$-oxide and the S-oxide of desmethyl-ADT (dmADT, 5-(p-hydroxyphenyl)$3 H$-1,2-dithiole-3-thione), and of p-methoxy-acetophenone (pMA) and p-hydroxy-acetophenone (pHA), in addition to the previously described metabolites, dmADT, anethole dithiolone (ADO, 5(p-methoxyphenyl)-3H-1,2-dithiole-3-one) and its demethylated derivative dmADO [5-(p-hydroxyphenyl)-3H-1,2-dithiole-3-one]. The
\end{abstract}

\section{Introduction}

Anethole dithiolethione (ADT, 5-(p-methoxyphenyl)-3H-1,2dithiole-3-thione; formula in Fig. 1) is a drug that has been marketed in many countries for many years and used in human therapy for its choleretic and sialogogic properties (Christen, 1995; Nagano and Takeyama, 2001). ADT also exhibits chemoprotective effects against cancer and various kinds of toxicity caused by some drugs and xenobiotics (Mansuy et al., 1986; Warnet et al., 1989; Reddy et al., 1993; Christen, 1995; Dollo et al., 1999; Lam et al., 2002; Kwak et al., 2003; Pouzaud et al., 2004; Zhang and Munday, 2008; Brooks et al., 2009). These chemoprotective effects appear to be mainly due to its antioxidant properties (Mansuy et al., 1986; Christen, 1995; Khanna et al., 1998) and its activity as a Nrf2 inducer, resulting in an increase of the GSH level and of the phase II detoxifying enzymes (Lee and Surh, 2005; Giustarini et al., 2014)

ADT and its $O$-demethylated derivative dmADT [5-(p-hydroxyphenyl)$3 \mathrm{H}$-1,2-dithiole-3-thione] were also extensively used as $\mathrm{H}_{2} \mathrm{~S}$ donors, and coupling of the $\mathrm{OH}$ group of dmADT with numerous anti-inflammatory drugs have led to a variety of compounds described for their $\mathrm{H}_{2} \mathrm{~S}$ donor properties and their therapeutic effects (Chen et al., 2010;

https://doi.org/10.1124/dmd.118.082545.

S This article has supplemental material available at dmd.aspetjournals.org. microsomal metabolism of ADO under identical conditions led to dmADO and to pMA and pHA. The metabolites of ADT derive from two competing oxidative pathways: an 0 -demethylation catalyzed by cytochromes P450 and an S-oxidation mainly catalyzed by flavindependent monooxygenases (FMO) and, to a minor extent, by CYP enzymes. The most active human CYP enzymes for ADT demethylation appeared to be CYP1A1, 1A2, 1B1, 2C9, 2C19, and 2E1. ADT $S$-oxidation is catalyzed by FMO 1 and 3 , and to a minor extent by CYP enzymes such as CYP3A4.

ABBREVIATIONS: ADO, 5-(p-methoxyphenyl)-3H-1,2-dithiole-3-one; ADT, 5-(p-methoxyphenyl)-3H-1,2-dithiole-3-thione; ADTSO, 5-(p-methoxyphenyl)-3H-1,2-dithiole-3-thione sulfoxide; Bz-ImH, N-benzyl-imidazole; CYP, cytochrome P450 enzyme; DEXA, dexamethasone; dmADO, 5-(p-hydroxyphenyl)-3H-1,2-dithiole-3-one; dmADT, 5-(p-hydroxyphenyl)-3H-1,2-dithiole-3-thione; dmADTSO, 5-(p-hydroxyphenyl)-3H-1,2-dithiole3-thione sulfoxide; FMO, flavin-dependent monoxygenase; HLM, human liver microsomes, HPLC-MS/MS, high-performance liquid chromatography with tandem mass spectrometry; $\beta$-NF, $\beta$-naphthoflavone; PB, phenobarbital; pHA, 4-hydroxy-acetophenone; pMA, 4-methoxy-acetophenone; RLM, rat liver microsomes. 


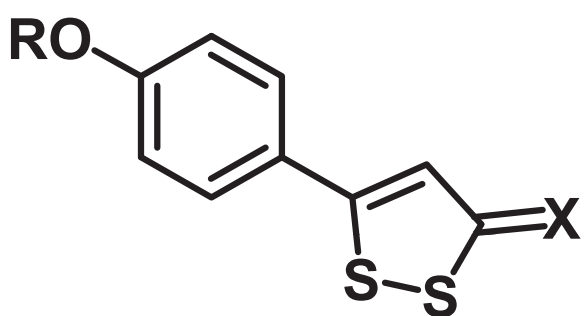

ADT

$\mathbf{X}=\mathbf{S}$

$\mathbf{R}=\mathbf{C H}_{3}$

dmADT

$\mathbf{X}=\mathbf{S}$

$\mathbf{R}=\mathbf{H}$

ADTSO

$\mathbf{X}=\mathbf{S O}$

$\mathbf{R}=\mathbf{C H}_{3}$

dmADTSO

$\mathbf{X}=\mathbf{S O}$

$\mathbf{R}=\mathbf{H}$

ADO

$\mathbf{X}=\mathbf{O}$

$\mathbf{R}=\mathbf{C H}_{3}$

dmADO

$\mathbf{R}=\mathbf{H}$
Fig. 1. Formula of ADT and some of its metabolites.

derive from two competing oxidative pathways occurring on ADT: an $O$-demethylation catalyzed by cytochrome P450 enzymes (CYP) and an $S$-oxidation catalyzed by flavin-dependent monooxygenases (FMO) and CYP enzymes. Finally, a study of the oxidation of ADT by recombinant human liver microsomal CYP and FMO enzymes allowed us to compare the abilities of those enzymes to catalyze ADT oxidation.

\section{Materials and Methods}

General Reagents. ADT was purchased from APIChem Technology (Hangzhou, Zhejiang, People's Republic of China). NADPH, NADP, G6P, G6PDH, miconazole, $N$-benzyl-imidazole (Bz-ImH), pHA, pMA, and all other chemicals were purchased from Sigma-Aldrich (Saint-Quentin Fallavier, France) and were of the highest commercially available purity. High-performance liquid chromatography-grade acetonitrile and methanol were obtained from SDS (Peypin, France).

Synthesis of Authentic Samples. DmADT was prepared by heating ADT in the presence of pyridine hydrochloride for 30 minutes at $215^{\circ} \mathrm{C}$, as described elsewhere (Chen et al., 2010). ADO and dmADO were prepared by treatment of $\mathrm{ADT}$ and dmADT, respectively, in the presence of mercuric acetate as described elsewhere (Klingsberg, 1972). ADTSO and dmADTSO were prepared from ADT and dmADT, respectively, by treatment with 3-chloroperbenzoïc acid at $0^{\circ} \mathrm{C}$ for 1 hour in dichloromethane, as described elsewhere (Perez and Kresze, 1981; Biard et al., 1992).

All derivatives displayed ${ }^{1} \mathrm{H}$ NMR (Supplemental Table 1), UV-visible (Supplemental Table 2) and high-resolution mass spectra (Supplemental Fig. 1) in accordance with their structures.

Origin of Microsomes and Recombinant Enzymes. Rat liver microsomes (RLM) were prepared as previously reported elsewhere (Kremers et al., 1981) from male Sprague-Dawley rats (Charles River, L'Arbresle, France) treated either with phenobarbital (PB) $\left(20 \mathrm{mg} . \mathrm{kg}^{-1}\right.$, in $0.9 \% \mathrm{NaCl}$ i.p. for 4 days), $\beta$-naphthoflavone $(\beta-\mathrm{NF})$, or dexamethasone (DEXA) (each $50 \mathrm{mg} \cdot \mathrm{kg}^{-1}$ in corn oil i.p. for 4 days). Recombinant CYP1A1, 1A2, 1B1, 2A6, 2C9, 2C19, 2D6, 2E1, and $3 \mathrm{~A} 4$, coexpressed in baculovirus-transfected insect cells with human cytochrome P450 oxidoreductase and cytochrome b5 (Supersomes) were obtained from Corning (Amsterdam, the Netherlands). Human liver microsomes (HLM) and recombinant FMO1 and FMO3 were also from Corning. The protein concentrations were determined by the Bradford assay with bovine serum albumin as a standard (Bradford, 1976). Cytochrome P450 contents were determined by the method of Omura and Sato (1964).

Typical Microsomal Incubation Procedures. The standard oxidation reactions were conducted in $50 \mathrm{mM}$ potassium phosphate buffer $(\mathrm{pH}$ 7.4) containing $0.1 \mathrm{mM}$ EDTA, microsomal proteins (usual concentration $3 \mu \mathrm{M}$ CYP), and $0.1 \mathrm{mM}$ substrate. The mixtures were incubated for 2 minutes at $37^{\circ} \mathrm{C}$, and the reactions (final volumes $200 \mu \mathrm{l}$ ) were started by the addition of NADPH $(1 \mathrm{mM})$ and a NADPH regenerating system $(0.5 \mathrm{mM}$ NADP $+5 \mathrm{mM} \mathrm{G6P}+$ $1 \mathrm{U} / \mathrm{ml}$ G6PDH). The usual incubations were performed for $0-120$ minutes at $37^{\circ} \mathrm{C}$ and were quenched by the addition of $100 \mu 1$ of a cold acetonitrile-acetic acid $(10: 1 \mathrm{v} / \mathrm{v})$ mixture.

The reaction mixtures were centrifuged $(10,000 \mathrm{~g}, 10$ minutes) to sediment the precipitated proteins, and aliquots of the supernatants were injected onto the high-performance liquid chromatography with tandem mass spectrometry (HPLC-MS/MS) system. Incubations of ADT and ADO with recombinant CYP or FMO enzymes were performed under identical conditions except that the incubation mixtures contained 20 pmol of recombinant CYP enzyme or $0.2 \mathrm{mg} / \mathrm{ml}$ FMO enzyme. The control experiments were performed under identical conditions but without protein or without the NADPH and NADPH regenerating system.

Large-scale (100 ml) incubations of ADT in the presence of liver microsomes from PB-pretreated rats were performed as previously described and were extracted with ethyl acetate. After evaporation of the solvent, ADT and its metabolites were separated on a Hypersil C18 column $(250 \times 7.5 \mathrm{~mm}, 5 \mu \mathrm{m}$; SFCC, Eragny, France). Elution was performed under isocratic condition using a mixture of water/methanol/acetic acid (60/40/1, v/v) at a flow rate of $3 \mathrm{ml} / \mathrm{min}$, and UV detection was performed at $310 \mathrm{~nm}$.

HPLC-MS/MS Analyses of Metabolites. The supernatants were analyzed on a Surveyor HPLC system including a photodiode array detector and coupled to a LCQ Advantage ion trap mass spectrometer (Thermo, Les Ulis, France). HPLC separations were achieved on a Gemini C18 column $(100 \times 2 \mathrm{~mm}, 3 \mu \mathrm{m}$; Phenomenex, Le Pecq, France). Elution (flow rate $250 \mu \mathrm{l} / \mathrm{min}$ ) was performed using a mixture of solvent $\mathrm{A}$ (water $+0.1 \%$ formic acid) and $\mathrm{B}$ (acetonitrile + $0.1 \%$ formic acid) with the following gradient conditions: $10 \% \mathrm{~B}$ for 1 minute, linear gradient to $80 \%$ B in 18 minutes, linear gradient to $100 \%$ B in 1 minute,

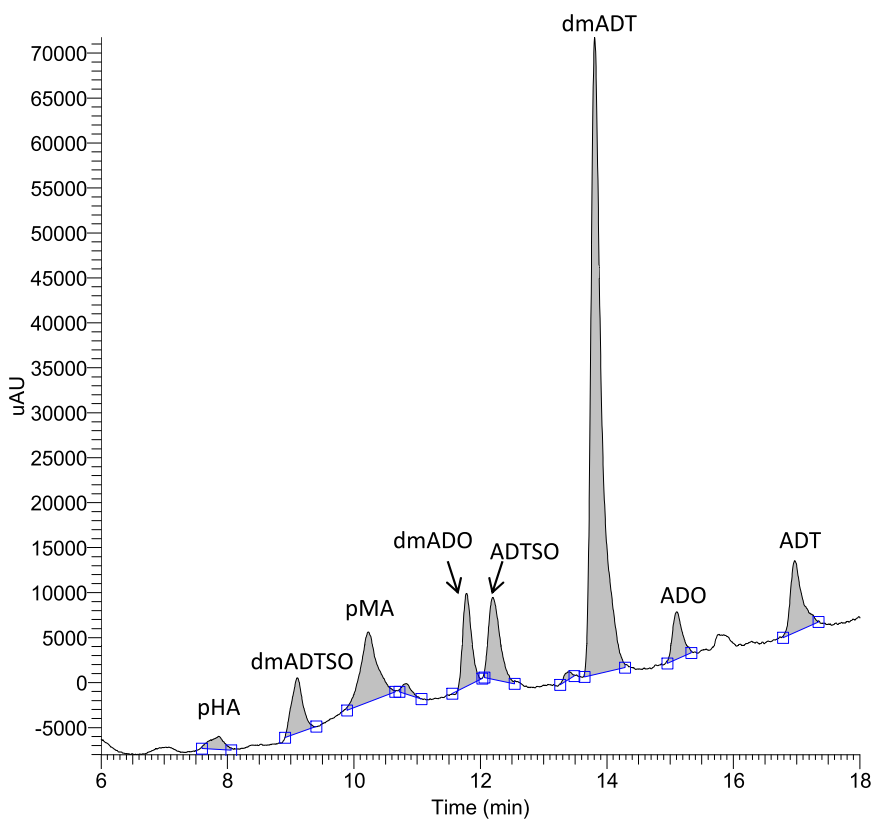

Fig. 2. HPLC chromatogram with photodiode array-detection from representative 2-hour incubation at $37^{\circ} \mathrm{C}$ of $100 \mu \mathrm{M}$ ADT with liver microsomes from $\beta$-NFpretreated rats $(3.0 \mu \mathrm{M}$ P450) in the presence of a NADPH-generating system. The incubation was conducted, treated, and analyzed by HPLC-MS/MS as described in Materials and Methods. The little blue squares appearing along the baseline are integration points. 
holding at $100 \% \mathrm{~B}$ for 3 minutes, returning to $10 \% \mathrm{~B}$ in 0.1 minute, and re-equilibration at $10 \% \mathrm{~B}$ for 5 minutes. The column effluent was directed to the ion source from 3 to 23 minutes after injection to reduce contamination.

Mass spectra were obtained by electrospray ionization in the positive detection mode under the following conditions. Source parameters were capillary temperature, $250^{\circ} \mathrm{C}$; capillary voltage, $6 \mathrm{~V}$; spray voltage, $4.5 \mathrm{kV}$; primary gas flow, 20 a.u.; and auxiliary gas flow, 5 a.u. Mass spectra were recorded with a resolution of 1 a.m.u., with a frequency of 50 milliseconds.

The range of masses scanned for the total-ion chromatogram was $m / z$ 120-600. For all products, the indicated molecular ions corresponded to $\mathrm{M}+\mathrm{H}^{+}$(i.e., ADT, $\mathrm{m} / \mathrm{z} 241, \mathrm{ADO}, \mathrm{m} / \mathrm{z} 225)$.

After data acquisition, HPLC-MS/MS chromatograms and UV-Vis spectra (230-550 nm) were analyzed with Excalibur LC Device 2.2.0 software (Thermo). Quantitation of ADT and of its metabolites was performed by integration of UV-visible spectra using calibration curves obtained from incubations of authentic compounds incubated, worked up, and analyzed in an identical fashion to that previously described, except that NADPH and the NADPH-regenerating system were omitted.
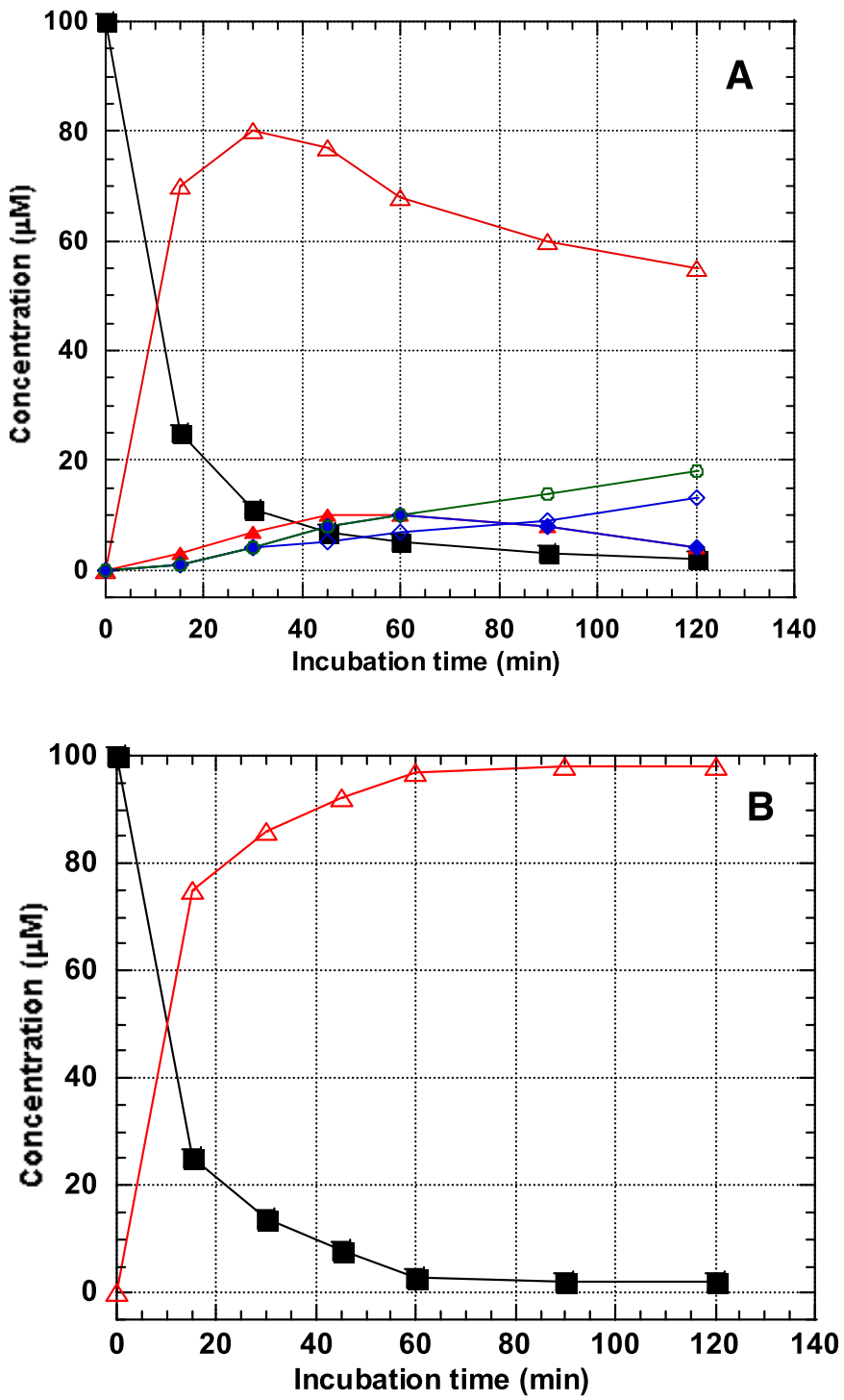

Fig. 3. (A) Representative kinetics of ADT metabolism by liver microsomes from $\beta$-NF-pretreated rats $(3.0 \mu \mathrm{M}$ P450) under conditions indicated in Materials and Methods. (B) Kinetics of an identical incubation containing $5 \mathrm{mM}$ GSH. ADT, black squares; dmADT, red empty triangles; dmADO, blue diamonds; ADTSO, red filled triangles; $\mathrm{ADO}$, blue filled circles; pMA, green empty circles.

\section{Results and Discussion}

Metabolism of ADT by Rat and Human Liver Microsomes. The HPLC-MS/MS chromatogram of incubates of $100 \mu \mathrm{M}$ ADT with liver microsomes from rats pretreated with $\beta-\mathrm{NF}$ in the presence of an NADPH generating system (Fig. 2) showed the formation of the previously described metabolites (Gmelin and Lagler, 1963; Masoud and Bueding, 1983; Hayashi et al., 1990; Chen et al., 2013): dmADT as a major metabolite and $\mathrm{ADO}$ and $\mathrm{dmADO}$ in smaller amounts. It also showed the formation of four other metabolites: ADTSO and dmADTSO, resulting from an $S$-oxidation of the $\mathrm{C}=\mathrm{S}$ moiety of ADT and dmADT, respectively, and pMA and pHA, two compounds resulting from the cleavage of the dithiolthione ring with loss of a carbon atom. All these metabolites were obtained from semipreparative HPLC and completely identified by comparison of their HPLC retention times, UV-visible, MS and ${ }^{1} \mathrm{H}$ NMR spectra with those of authentic samples that were synthesized as indicated in Materials and Methods or commercially obtained in the case of pMA and pHA.

It is likely that the $S$-oxide ADTSO is the oxygenated metabolite of ADT mentioned by Chen et al. (2013). Figure 3A shows a typical kinetic study of the metabolism of ADT in the presence of liver microsomes from rats pretreated with $\beta$-NF. First, ADT was predominantly metabolized into dmADT and small amounts of ADTSO, ADO, dmADO, and pMA. DmADT, ADTSO, and ADO then decreased with a concomitant increase in $\mathrm{dmADO}$ and pMA formation. Identical incubations of ADT but in the absence of microsomes or NADPH did not lead to any formation of those metabolites (data not shown).

Table 1 compares the amounts of the ADT metabolites formed upon 2-hour incubations of ADT with a NADPH regenerating system and liver microsomes from rats pretreated by several inducing agents, $\beta-\mathrm{NF}$, $\mathrm{PB}$, or DEXA, or with HLM. It shows that the same metabolites are formed with the three types of RLM. However, it is noteworthy that liver microsomes from DEXA-pretreated rat are less active for ADT oxidation (25\% residual ADT instead of $6 \%-7 \%$ in the case of $\beta$-NFor PB-treated rats after 2 hours). Moreover, they led to far fewer metabolites derived from an ADT $O$-demethylation (22\% compared with $75 \%$ total metabolites instead of about $60 \%$ compared with $94 \%$ total metabolites in the case of the two other RLM) (Table 1).

HLM predominantly catalyzed the $O$-demethylation of ADT $(65 \%$ of all metabolites), but with a lower activity than the $\beta$-NF and PB-pretreated RLM (30\% residual ADT after 2 hours) (Table 1).

TABLE 1

Metabolism of ADT by liver microsomes from rats pretreated with differen inducing agents and by HLM

Data are expressed as percentage of metabolites formed after 2 hours of incubation of $100 \mu \mathrm{M}$ ADT in the presence of $\beta$-NF-, PB-, and DEXA-pretreated rat liver microsomes, or HLM, as indicated in Materials and Methods. Data are mean \pm S.D. from two to five experiments. The amounts of pHA were too low to be accurately quantified.

\begin{tabular}{lrrrr}
\hline \multirow{2}{*}{ Compounds } & \multicolumn{4}{c}{$\%$ Total Metabolites } \\
\cline { 2 - 5 } & \multicolumn{1}{c}{$\beta$-NF } & \multicolumn{1}{c}{ PB } & \multicolumn{1}{c}{ DEXA } & HLM \\
\hline ADT & $7 \pm 2$ & $6 \pm 2$ & $25 \pm 4$ & $30 \pm 5$ \\
dmADT & $53 \pm 5$ & $45 \pm 4$ & $12 \pm 3$ & $46 \pm 5$ \\
ADTSO & $4 \pm 2$ & $9 \pm 2$ & $18 \pm 3$ & $5 \pm 2$ \\
ADO & $4 \pm 1$ & $2 \pm 1$ & $15 \pm 3$ & $5 \pm 3$ \\
dmADTSO & $3 \pm 2$ & $4 \pm 2$ & $4 \pm 2$ & ND \\
dmADO & $11 \pm 1$ & $6 \pm 2$ & $6 \pm 2$ & ND \\
pMA & $16 \pm 2$ & $25 \pm 3$ & $18 \pm 2$ & $12 \pm 3$ \\
\hline
\end{tabular}

ADO, 5-(p-methoxyphenyl)-3H-1,2-dithiole-3-one; ADT， 5-(p-methoxyphenyl)-3H-1,2 dithiole-3-thione; ADTSO, 5-(p-methoxyphenyl)-3H-1,2-dithiole-3-thione sulfoxide; DEXA, dexamethasone; dmADO, 5-(p-hydroxyphenyl)-3H-1,2-dithiole-3-one; dmADT, 5-(p-hydroxyphenyl)-3H-1,2-dithiole-3-thione; dmADTSO, 5-(p-hydroxyphenyl)-3H-1,2-dithiole-3-thione sulfoxide; HLM, human liver microsomes, ND, not detected; $\beta$-NF, $\beta$-naphthoflavone; PB, phenobarbital; pMA, 4-methoxy-acetophenone. 
Interestingly, incubation of ADT with liver microsomes from $\beta$-NFtreated rats in the presence of a NADPH-regenerating system and of $5 \mathrm{mM}$ glutathione almost exclusively led to dmADT (Fig. 3B). Identical results were observed with HLM (data not shown).

The lack of formation of ADTSO and metabolites deriving from ADTSO, such as ADO and pMA, in the presence of GSH could be explained by the reduction of the sulfoxide function of ADTSO by GSH back to ADT. Actually, reaction of $100 \mu \mathrm{M}$ ADTSO with $1 \mathrm{mM} \mathrm{GSH}$ in $50 \mathrm{mM}$ potassium phosphate buffer $(\mathrm{pH} 7.4)$ containing $0.1 \mathrm{mM}$ EDTA for 30 minutes at $37^{\circ} \mathrm{C}$ almost quantitatively led to ADT. In a similar manner, reaction of dmADTSO with GSH under identical conditions almost exclusively led to dmADT (data not shown).

Metabolism of ADO by Liver Microsomes. To assess the sequential metabolism of ADT, incubations were conducted using $\mathrm{ADO}$ as the starting compound. Metabolism of ADO by rat or human liver microsomes under conditions identical to those used previously for ADT led to the three metabolites already observed in the case of ADT: $\mathrm{dmADO}, \mathrm{pMA}$, and pHA. Figure 4 shows the kinetics of formation of those metabolites in incubations of $\mathrm{ADO}$ with $\beta$-NF-treated rat liver microsomes and HLM (Fig. 4, respectively). These data show that pMA is a metabolite of ADO and suggest that $\mathrm{pHA}$ derives from dmADO. Accordingly, incubation of dmADO with the same microsomes led to pHA as a major metabolite (data not shown).

These data about ADT and ADO microsomal metabolism indicate that ADT metabolites derive from two pathways for oxidation of the molecule: an $O$-demethylation and an $S$-oxidation, leading respectively to dmADT and ADTSO as primary metabolites (Fig. 5). ADTSO should then lead to ADO by oxidative desulfuration in a manner similar to what was reported for the oxidative desulfuration of compounds containing a $\mathrm{C}=\mathrm{S}$ moiety (Hanzlik and Cashman, 1983) and to pMA deriving from ADO as shown in Fig. 5.

The further microsomal metabolism of the other primary metabolite dmADT should be similar to that of ADT, with the formation of metabolites deriving from an $S$-oxidation: dmADTSO, dmADO, and pHA (Fig. 5). Accordingly, metabolism of dmADT with the same microsomes led to dmADTSO, dmADO, and pHA as major metabolites (data not shown).

Nature of the Microsomal Enzymes Involved in the Metabolism of ADT. To determine the enzymes involved in the human liver metabolism of the drug ADT, incubations of ADT with several recombinant human CYP and FMO enzymes involved in xenobiotics metabolism were performed. Table 2 shows that CYP enzymes of family 1 (CYP1A1, 1A2, and 1B1) and CYP2C19 are very good catalysts for ADT oxidation ( $O$-demethylation $+S$-oxidation). CYP2C9, 2D6, 2E1, and 3A4 are also active for ADT oxidation, even though less than those of family 1 , whereas CYP2A6 is much less active. Moreover, the observed $O$-demethylation $/ S$-oxidation ratio very much varied as a function of the involved CYP enzymes. This ratio was much in favor of $O$-demethylation in the case of CYP1B1, $2 \mathrm{C} 19,1 \mathrm{~A} 2,2 \mathrm{C} 9,1 \mathrm{~A} 1$, and 2E1 (values from 25 to 4 ), whereas it was in favor of $S$-oxidation for CYP2D6 and 3A4 (values of about 0.5 and close to 0 , respectively).

Interestingly, recombinant FMO enzymes 1 and 3 failed to catalyze ADT $O$-demethylation, as expected (Cashman, 1995; Cashman and Zhang, 2006), but they were active for ADT $S$-oxidation (Table 2). Actually, inactivation of microsomal FMO enzymes by preheating of $\mathrm{HLM}$ at $45^{\circ} \mathrm{C}$ for 10 minutes (Cashman and Zhang, 2006) led to a $60 \%$ decrease of the formation of ADTSO and ADO whereas it led to an increase of the formation of the $O$-demethylated product dmADT (data not shown). Moreover, incubation of ADT with HLM in the presence of an usual CYP inhibitor, $N$-benzyl-imidazole $(1 \mathrm{mM})$ (Testa and Jenner, 1981; Correia and Ortiz de Montellano, 2005), led to a 60\% inhibition of
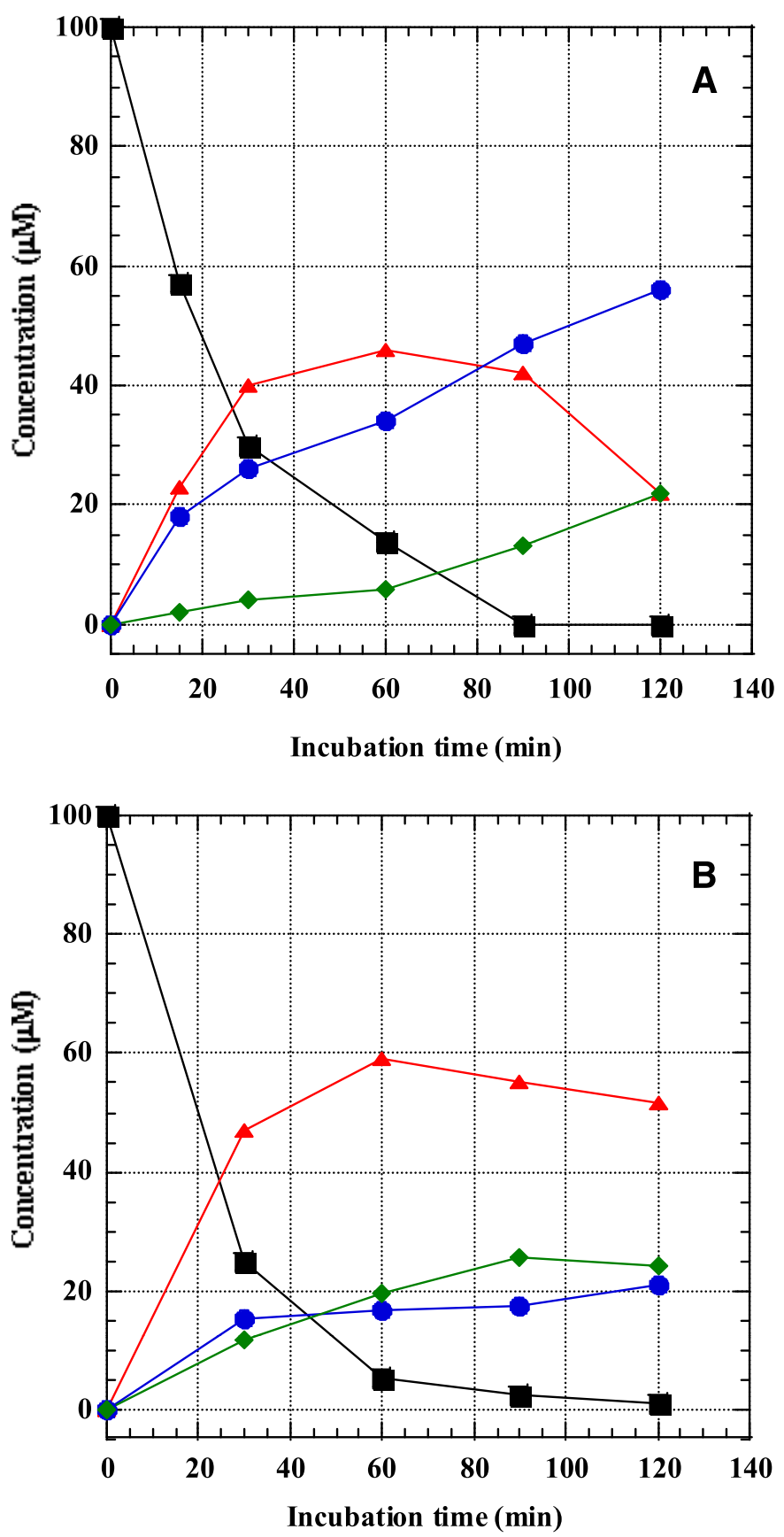

Fig. 4. Kinetics of ADO metabolism by liver microsomes from (A) $\beta$-NF-pretreated rats $(3.0 \mu \mathrm{M}$ P450) or by (B) HLM $(2.2 \mu \mathrm{M}$ P450). Conditions indicated in Materials and Methods. ADO, black squares; dmADO, red triangles; pMA, blue circles; pHA, green diamonds.

dmADT formation and only led to a $20 \%$ decrease of the ADTSO formation (data not shown). These data indicated that ADT $S$-oxidation was mainly catalyzed by FMO enzymes and to a minor extent by CYP enzymes.

The results of Table 2 also show that ADO was formed upon oxidation of ADT by most recombinant human CYP and FMO enzymes, indicating that both enzymes are also able to catalyze the oxidation of ADTSO to ADO. We have confirmed this point in the particular case of recombinant CYP3A4. Incubations of $100 \mu \mathrm{M}$ ADTSO for 1 hour at $37^{\circ} \mathrm{C}$ in the presence of $0.2 \mu \mathrm{M}$ recombinant CYP3A4 and $1 \mathrm{mM}$ $\mathrm{NADPH}$ led to ADO as the major product (data not shown). 


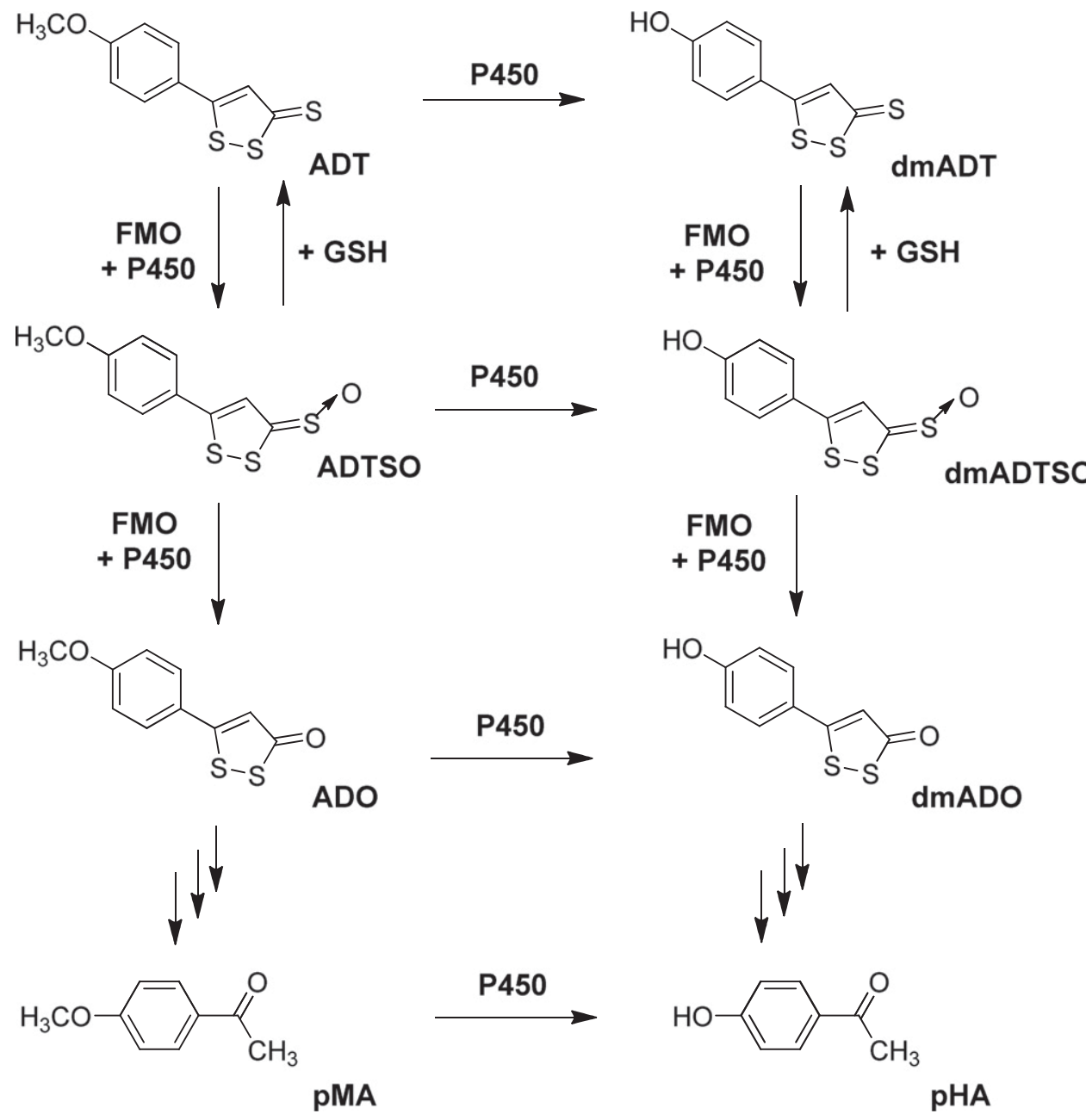

Fig. 5. Reactions involved in the metabolism of ADT and ADO by HLM and RLM.

These data indicate that the products formed upon metabolism of ADT by HLM derive from two pathways: an oxidative CYP-catalyzed $O$-demethylation (CYP enzymes of family 1 and CYP2C19, 2C9, and $2 \mathrm{E} 1$ being the most active ones) and an $S$-oxidation of the $\mathrm{C}=\mathrm{S}$ group of ADT catalyzed by FMO enzymes and by some CYP enzymes such as CYP3A4. This should also be true for ADT metabolism by RLM as the greatest $O$-demethylation/S-oxidation ratio was observed in the case of microsomes of rats pretreated with $\beta-\mathrm{NF}$, an inducer of P450 enzymes from family 1 , the lowest $O$-demethylation $/ S$-oxidation ratio being observed in the case of microsomes of rats pretreated with DEXA, an usual inducer of P450 enzymes from the 3A subfamily (Williams et al., 2005).

\section{Conclusions}

The reinvestigation of ADT metabolism and study of ADO metabolism by rat and human liver microsomes has clearly established the formation of new metabolites, ADTSO, dmADTSO, pMA, and pHA, in addition to the previously described metabolites, dmADT, ADO, and dmADO (Gmelin and Lagler; 1963; Hayashi et al., 1990; Chen et al., 2013). They also showed that all these metabolites derive from two primary pathways: a CYP-dependent $O$-demethylation of ADT, and an $S$-oxidation of the $\mathrm{C}=\mathrm{S}$ group of ADT that is catalyzed both by FMO and CYP enzymes. The use of recombinant human P450 enzymes showed that CYP enzymes of family 1 and CYP2C19, 2C9, and 2E1 are the most active ones for ADT $O$-demethylation. ADO and the opened products having lost one carbon and the three sulfur atoms of ADT, pMA, and $\mathrm{pHA}$ are derived from the ADT $S$-oxidation pathway that can be catalyzed by FMO enzymes and some CYP enzymes such as CYP3A4. The reactions involved in the passage from ADO to pMA are under study.

TABLE 2

Metabolism of ADT with microsomes from insect cells expressing various recombinant human CYP and FMO enzymes (Supersomes)

Percentage of ADT or metabolite yields \pm S.D. from two to four experiments, from $100 \mu \mathrm{M}$ ADT after 2 hours of incubation in the presence of $0.2 \mu \mathrm{M}$ recombinant CYP enzymes or from 1 hour of incubations containing $1 \mathrm{mg} / \mathrm{ml}$ recombinant FMO. Quantitation of ADT and of its metabolites was performed by integration of UV-visible spectra using calibration curves as described in Materials and Methods.

\begin{tabular}{lcccccc}
\hline \multicolumn{1}{c}{ Enzyme } & ADT & dmADT & ADTSO & ADO & dmADO & pMA \\
\hline CYP1A1 & $36 \pm 2$ & $58 \pm 5$ & ND & $8 \pm 2$ & $2 \pm 1$ & $1 \pm 1$ \\
CYP1A2 & $18 \pm 2$ & $75 \pm 5$ & ND & $3 \pm 2$ & $4 \pm 2$ & $1 \pm 1$ \\
CYP1B1 & $22 \pm 4$ & $74 \pm 5$ & ND & $3 \pm 2$ & $1 \pm 1$ & ND \\
CYP2A6 & $93 \pm 6$ & ND & ND & $6 \pm 2$ & ND & ND \\
CYP2C9 & $73 \pm 6$ & $23 \pm 4$ & ND & $3 \pm 2$ & $1 \pm 1$ & ND \\
CYP2C19 & $21 \pm 4$ & $75 \pm 6$ & ND & $3 \pm 1$ & $1 \pm 1$ & ND \\
CYP2D6 & $48 \pm 5$ & $16 \pm 4$ & ND & $28 \pm 4$ & ND & $6 \pm 2$ \\
CYP2E1 & $44 \pm 5$ & $35 \pm 5$ & ND & $7 \pm 2$ & $8 \pm 3$ & $4 \pm 2$ \\
CYP3A4 & $47 \pm 5$ & ND & ND & $40 \pm 5$ & ND & $13 \pm 4$ \\
FMO1 & $72 \pm 6$ & ND & $4 \pm 2$ & $16 \pm 4$ & ND & $6 \pm 2$ \\
FMO3 & $93 \pm 5$ & ND & $4 \pm 2$ & $3 \pm 1$ & ND & ND
\end{tabular}

ADO, 5-(p-methoxyphenyl)-3H-1,2-dithiole-3-one; ADT, 5-(p-methoxyphenyl)-3H-1,2 dithiole-3-thione; ADTSO, 5-(p-methoxyphenyl)-3H-1,2-dithiole-3-thione sulfoxide; dmADO, 5-(p-hydroxyphenyl)-3H-1,2-dithiole-3-one; dmADT， 5-(p-hydroxyphenyl)-3H-1,2-dithiole-3thione; ND, not detected; pMA, 4-methoxy-acetophenone. 


\section{Acknowledgments}

We thank A. Hessani for her help in HPLC-MS/MS experiments, and M. Jaouen and B. Ramassamy for their technical assistance.

\section{Authorship Contributions}

Participated in research design: Dansette, Boucher, Mansuy, Christen.

Conducted experiments: Dulac, Sassi, Nagarathinan, Boucher.

Contributed new reagents or analytic tools: Dulac, Sassi, Boucher, Dansette.

Performed data analysis: Dulac, Sassi, Boucher, Dansette, Mansuy.

Wrote or contributing to the writing of the manuscript: Mansuy, Boucher,

Dansette.

\section{References}

Biard D, Christen MO, Dansette P, Jasserand D, Mansuy D, and Sassi A (1992) inventors, Abbott Products $\mathrm{GmbH}$, assignee. 1,2-Dithiol-3-thion- $S$-oxide compounds and pharmaceutical compositions. U.S. Patent 5,096,920. 1992 March 17.

Bradford MM (1976) A rapid and sensitive method for the quantitation of microgram quantities of protein utilizing the principle of protein-dye binding. Anal Biochem 72:248-254.

Brooks SC, III, Brooks JS, Lee WH, Lee MG, and Kim SG (2009) Therapeutic potential of dithiolethiones for hepatic diseases. Pharmacol Ther 124:31-43.

Cashman JR (1995) Structural and catalytic properties of the mammalian flavin-containing monooxygenase. Chem Res Toxicol 8:166-181.

Cashman JR and Zhang J (2006) Human flavin-containing monooxygenases. Annu Rev Pharmacol Toxicol 46:65-100.

Chen MH, Liu MH, Di B, and Su MX (2013) Anethol trithione metabolites and their mutual transformation. Chinese J New Drugs 22:2328-2331.

Chen P, Luo Y, Hai L, Qian S, and Wu Y (2010) Design, synthesis, and pharmacological evaluation of the aqueous prodrugs of desmethyl anethole trithione with hepatoprotective activity. Eur J Med Chem 45:3005-3010.

Christen MO (1995) Anethole dithiolethione: biochemical considerations. Methods Enzymol 252 316-323.

Correia MA and Ortiz de Montellano PR (2005) Inhibition of cytochromes P450 enzymes, in Cytochrome P450, Structure, mechanism, and Biochemistry, 3rd ed. (Ortiz de Montellano PR ed) pp 247-322, Kluwer Academic/Plenum, New York.

Couto M, de Ovalle S, Cabrera M, Cerecetto H, and González M (2015) Searching phase II enzymes inducers, from Michael acceptor-[1,2]dithiolethione hybrids, as cancer chemopreventive agents. Future Med Chem 7:857-871.

Dollo G, Le Corre P, Chollet M, Chevanne F, Bertault M, Burgot JL, and Le Verge R (1999) Improvement in solubility and dissolution rate of 1,2-dithiole-3-thiones upon complexation with beta-cyclodextrin and its hydroxypropyl and sulfobutyl ether-7 derivatives. J Pharm Sci 88: 889-895.

Giustarini D, Fanti P, Sparatore A, Matteucci E, and Rossi R (2014) Anethole dithiolethione lower the homocysteine and raises the glutathione levels in solid tissues and plasma of rats: a novel non-vitamin homocysteine-lowering agent. Biochem Pharmacol 89:246-254.

Gmelin R and Lagler F (1963) Tolerance and excretion of anetholtrithion. Arzneimittelforschung 13:130-133.

Hanzlik RP and Cashman JR (1983) Microsomal metabolism of thiobenzamide and thiobenzamide S-oxide. Drug Metab Dispos 11:201-205.

Hayashi T, Okuyama Y, Komura H, Morino A, Sugiyama M, and Nomura A (1990) Studies on the metabolic fate of anethole trithione. Iyakuhin Kenkyu 21:584-602.

Kashfi K and Olson KR (2013) Biology and therapeutic potential of hydrogen sulfide and hydrogen sulfide-releasing chimeras. Biochem Pharmacol 85:689-703.
Khanna S, Sen CK, Roy S, Christen MO, and Packer L (1998) Protective effects of anethole dithiolethione against oxidative stress-induced cytotoxicity in human Jurkat $\mathrm{T}$ cells. Biochem Pharmacol 56:61-69.

Klingsberg E (1972) The 1,2-Dithiolium cation. XI. Polycyclic dithiole and "no-bond resonance" compounds. J Org Chem 57:3226-3229.

Kremers P, Beaune P, Cresteil T, de Graeve J, Columelli S, Leroux JP, and Gielen JE (1981) Cytochrome P-450 monooxygenase activities in human and rat liver microsomes. Eur J Biochem 118:599-606.

Kwak MK, Wakabayashi N, Itoh K, Motohashi H, Yamamoto M, and Kensler TW (2003) Modulation of gene expression by cancer chemopreventive dithiolethiones through the Keap1Nrf2 pathway. Identification of novel gene clusters for cell survival. $J$ Biol Chem 278: $8135-8145$

Lam S, MacAulay C, Le Riche JC, Dyachkova Y, Coldman A, Guillaud M, Hawk E, Christen MO, and Gazdar AF (2002) A randomized phase IIb trial of anethole dithiolethione in smokers with bronchial dysplasia. J Natl Cancer Inst 94:1001-1009.

Lee JS and Surh YJ (2005) Nrf2 as a novel molecular target for chemoprevention. Cancer Lett 224 171-184.

Mansuy D, Sassi A, Dansette PM, and Plat M (1986) A new potent inhibitor of lipid peroxidation in vitro and in vivo, the hepatoprotective drug anisyldithiolthione. Biochem Biophys Res Commun 135:1015-1021.

Masoud AN and Bueding E (1983) Identification and quantitation of a metabolite of anetho dithiolthione in rat and mouse urine using high-performance liquid chromatography. $J$ Chromatogr A 276:111-119.

Nagano T and Takeyama M (2001) Enhancement of salivary secretion and neuropeptide (substance $\mathrm{P}$, alpha-calcitonin gene-related peptide) levels in saliva by chronic anethole trithione treatment. J Pharm Pharmacol 53:1697-1702.

Omura T and Sato R (1964) The carbon monoxide-binding pigment of liver microsomes. I. Evidence for its hemoprotein nature. J Biol Chem 239:2370-2378.

Perez MA and Kresze G (1981) 3H-1,2-Dithiol-3-thion-S-oxide. Liebigs Ann Chem 1981 1510-1512. DOI: $10.1002 /$ jlac.198119810823.

Pouzaud F, Christen MO, Warnet JM, and Rat P (2004) Anethole dithiolethione: an antioxidant agent against tenotoxicity induced by fluoroquinolones. Pathol Biol (Paris) 52 308-313.

Reddy BS, Rao CV, Rivenson A, and Kelloff G (1993) Chemoprevention of colon carcinogenesis by organosulfur compounds. Cancer Res 53:3493-3498.

Sassi A (1986) Metabolisme et origine des effets hepatoprotecteurs des dérives de l'anisyldithiolethione. Ph.D. thesis, University Paris-Sud, Paris, France.

Sparatore A, Santus G, Giustarini D, Rossi R, and Del Soldato P (2011) Therapeutic potential of new hydrogen sulfide-releasing hybrids. Expert Rev Clin Pharmacol 4:109-121.

Testa B and Jenner P (1981) Inhibitors of cytochrome P-450s and their mechanism of action. Drug Metab Rev 12:1-117.

Warnet JM, Christen MO, Thevenin M, Biard D, Jacqueson A, and Claude JR (1989) Protective effect of anethol dithiolthione against acetaminophen hepatotoxicity in mice. Pharmacol Toxicol 65:63-64.

Williams SN, Dunham E, and Bradfield CA (2005) Induction of cytochrome P450 enzymes, in Cytochrome P450, Structure, mechanism, and Biochemistry, 3rd ed. (Ortiz de Montellano PR ed) pp 323-346, Kluwer Academic/Plenum Publishers, New York.

Zhang Y and Munday R (2008) Dithiolethiones for cancer chemoprevention: where do we stand? Mol Cancer Ther 7:3470-3479.

Address correspondence to: Jean-Luc Boucher, Laboratoire de Chimie et Biochimie Pharmacologiques et Toxicologiques, UMR 8601 CNRS, University Paris Descartes, 45 rue des Saints Pères, 75006 Paris, France. E-mail: jean-luc. boucher@parisdescartes.fr 